
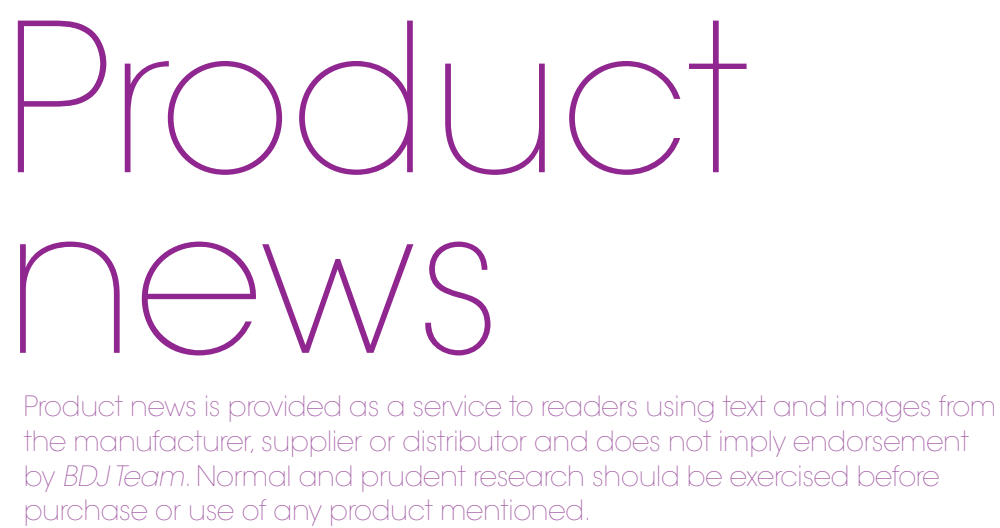

\title{
WHY NOT TAKE ON A DENTAL NURSE APPRENTICE?
}

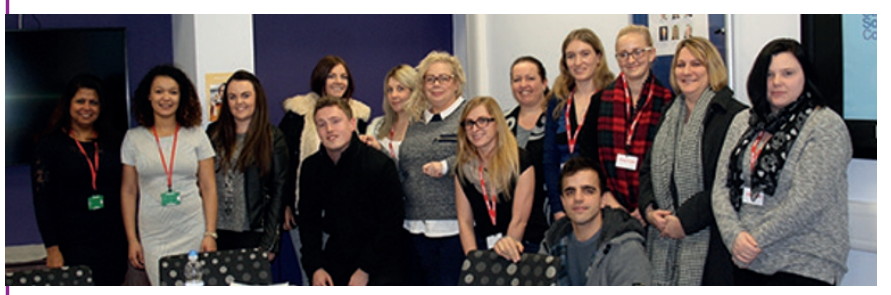

their studies and perform their role competently.

Attract new talent

to your team and

enjoy the rewarding experience of

Your team is a great resource with a wealth of knowledge and experience to pass on to apprentices, making them perfect teachers and mentors. As they become involved in training they will feel valued and respected, increasing their own personal development and job satisfaction.

The Dental Nursing Apprenticeship programme is an 18-month course combining practical dental nursing skills with theoretical knowledge. Apprentices mostly learn in the workplace, becoming part of the dental team with access to all the resources and support they need to complete offering a young person the chance to gain a nationally recognised qualification, which will set them on a path to a worthwhile career. Not only that, it's a golden opportunity to empower your existing team members.

The Dental Nursing Apprenticeship programme is delivered through Barnet and Southgate College with start dates in July and periodically throughout the year.

It's a win-win situation, so find out more about apprenticeships today.

For more information contact Barnet and Southgate College at on 02037644333 or visit www.barnetsouthgate.ac.uk.

\section{FREE ONLINE TOOTH WEAR CPD MODULE}

ESCARCEL, a recent pan-European study, amongst 3,187 subjects aged 18-35, concluded that 1 in 3 young adults suffer from tooth wear. In a survey of 200 dental professionals completed in $2013,84 \%$ said they see signs of erosive tooth wear on a weekly basis and $86 \%$ felt the condition is on the rise. This emphasises how common erosive tooth wear is throughout the population.

To help raise awareness of the risk factors for tooth wear associated with eating and drinking acidic foods and drinks found in today's diet, Pronamel are offering dental professionals access to a specially developed online module. Topics include identifying signs of tooth wear, condition management advice, the use of the Basic Erosive Wear Examination tool (BEWE) and the role of Pronamel in protection from the effects of acidic diets.

The Pronamel online CPD module is available in an easy to use format which is free of charge. Available 24 hours a day, you can access this module whenever is convenient. Completion of the module can contribute up to 1.5 hours towards your verifiable $\mathrm{CPD}$.

In addition, it provides information on the Pronamel range and how it can help protect patients from the effects of erosive tooth wear.

Visit www.gsk-dentalprofessionals.co.uk/ pronamelcpd 1 to complete the module now.
SPONGES THAT HOLD 40-50 TIMES THEIR WEIGHT IN BLOOD

Haemostasis is crucial for controlling blood flow during dental interventions. HYGITECH haemostatic sponges are made of high quality gelatine, highly processed and purified, offering good adhesion to the bleeding site, promoting the formation of the fibrin network essential to efficient coagulation. Resorption is complete in 3-4 weeks.

As a macro-porous sponge, HYGITECH haemostatic sponges are insoluble in water with a rapid absorption capacity, equivalent to 40-50 times their weight in blood or other liquids. HYGITECH sponges are easy to use and malleable; they are combined with an antibacterial agent; and they can be cut to fit the bleeding area. They are delivered in single sterile blister packs.

HYGITECH is a German manufacturer and distributor of specialised dentistry products, from dental instruments to surgical preparation to sterilisation.

Visit hygitech.uk or telephone 02038081110

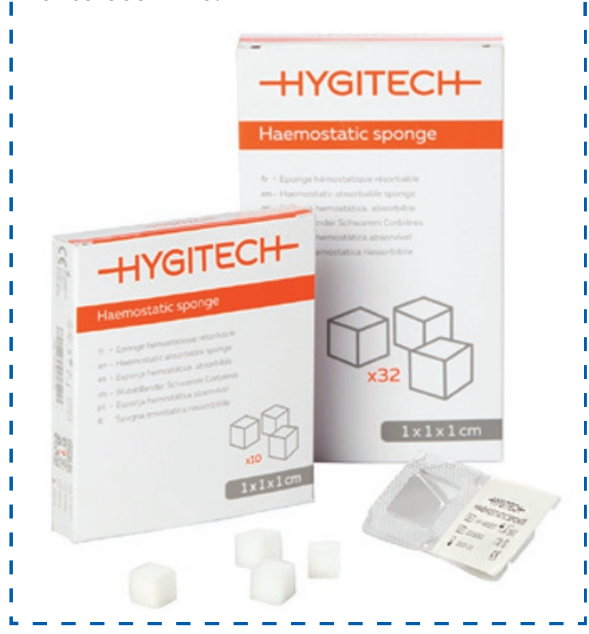

If you would like to promote your products or services direct to the dental industry in BDJ Team, call Andy May on 02078434785 or emaila.may@nature.com 